\title{
Enhancing student learning through Webinars and lecture capture tools
}

\section{H. T. Jadhav}

Department of Electrical Engineering

Rajarambapu Institute of Technology, Rajarmnagar

Tal- Walwa, Dist - Sangli

htj@ritindia.edu

\begin{abstract}
Due to development in the field of communication engineering and availability of low cost internet technology, the students in today's world wants learning resources in the form of video lectures and webinars. This requirement can be fulfilled by developing webinars and creating video lectures so that students with different learning styles can learn at their own pace. This can help enhance classroom experience and student learning. In this paper an experience regarding organization of series of webinars and development of video lectures to enhance classroom teaching learning is presented. After completion of course it is observed that, the Zoom which is an online meeting tool with microphone and screen sharing feature can help improve student learning with real time conversations. Moreover, to maximize learning experience and exploit use of technology, video content adding voice over to Power Point slides was developed and uploaded on YouTube to share with students for repeated watching and listening. The active engagement of students in class was found to be more than traditional chalkboard lecturing. It is observed, after analysis of grades awarded to students in written examination and course projects, that the performance of student was better than previous academic years. The feedback of students shows that learning through webinar is better than conventional classroom lectures.
\end{abstract}

Keywords: active learning, iPad, webinar, YouTube, Zoom

\section{Introduction}

During last few years, large number of technical institutions have been established in India due to the increasing demand for engineering education and availability of scholarship from state and central government for financially challenged students. During 1885-86, the student intake capacity was 0.17 and there were only 242engineering institutions in India (Choudhury, P. K., 2016) offering undergraduate engineering degree. The student intake capacity increased to 3.4 million with more than 3,045 institutes in the year 2019-2020. The other reason that more number of students have been registering for engineering education is because of availability of engineering institute in the close neighbourhood of their homes since the cost associated with lodging and boarding can be reduced. It has been noticed that students with good engineering aptitude do not prefer reputed private engineering institutes due to high tuition fees or remote location from their home towns, if they fails to make to premier Government Engineering institutes. This has resulted into less number of students in a particular classroom with ability to learn fast. Also the number of students traveling every day from their home town to education institute, to attend academic activities, have increased with the intention to save hostel and other expenses because of which most of the time and energy of these students is wasted in performing journey by public transport vehicles and it also affect their ability to study the courses on day-to-day basis due to travel fatigue. On the other hand, four years engineering education is offered through eight semesters and in order to include industry relevant courses in addition to all basic courses, it is necessary to cover large content in specific course so as to limit number of theory and laboratory courses. Therefore many slow learners in classroom fail to cope up the entire syllabus of specific course in 12-14 week time of semester. Moreover, the trend in, many autonomous technical institutes, is towards continuous assessment of course for better evaluation of student learning which require that all students including slow learners and fast learning should, understand the course and should the learning by answering questions associated with higher levels of blooms taxonomy(Krathwohl, D. R. 2002). This becomes very challenging for course instructor especially when the students are at first year level of engineering study since these students mostly study in annual system of education up to 12 th standard. Unfortunately the teaching learning process, in education system up to $12^{\text {th }}$ standard, in most of the part of country is still based on traditional lecturing and hence majority of students joining engineering education fail to participate in active learning process. It is noticed that the implementation of commonly known active learning methods such as think-pair-share, group discussion, Jigsaw, problem based learning etc.(Boud, D., 2013) may not be always help communicate the course all students at first year level. Such activities definitely help fast learners to participate in learning process however slow learners may find it difficult to align with learning process if the class size is very high. This may, sometimes, affect the teaching plan of course instructor as well if the number of slow learners are re in the class. Hence to complete the course syllabus effectively, sometimes course instructors are required to engage remedial classes to deal with slow learners 
however this may not be always possible since students may not be available for extra classes due to other academic requirements.

Since the cost of smart phones, computer and internet data has dropped significantly during last few years and hence many course instructors believes that the quality of learning and access to education at reduced cost can improved using technology in engineering education (Alexander, S., 2001). There are many good quality online learning resources and platforms available for learners, these days, such as NPTEL, Udemy, and YouTube etc. However these resources are mainly useful to fast learners since the content may not always help slow learners understand the topics presented may be due to gap between syllabus content or English accent.

Online teaching may be using real-time tools e.g. using video conferencing platforms Zoom, Go To Meeting, etc. and anytime, anywhere (asynchronous) interactions e.g YouTube, Udemy, Moodle etc. These are innovative approaches to conduct lectures, in an online, virtual or networked environment or facilitating learning using recorded lecture content in which the course instructor and students are not physically in close vicinity, but still interact with each other (Al-Shahrani, I., 2019). Moreover, the webinars other e-learning resources can help learners enhance their social presence in stress free environment and yet allow them to be part of lecture in personalized environment (Khairova, I. V., 2016).

Taking into account above mentioned constraints such as heterogeneous classroom, learning abilities and other concerns of students, this paper describes how technology helped enhance learning experience and student participation through series of webinars and recorded video lectures for a course offered at first year level.

\section{Course Design and Assessment Scheme}

Electrical Engineering (EE) is mandatory course taught in first semester to first year students of all undergraduate engineering programs. This course consists of six units. This course has 36 hours of lectures and 2 hours of laboratory work weekly. EE starts with the basic circuit analysis methods to solve dc circuits and AC circuits. This includes Kirchhoff's current and voltage laws, superposition, Thévenin's theorem, Norton's theorem, series/parallel circuits containing resistance, inductance and capacitance. These methods are then applied to study topics like transformers, Electrical motors and power electronic converters. Also, some of elementary level topics like electrical wires, cable, lamps, domestic wiring and low voltage switchgears etc are introduced in rest of the course. Most of the topics need good knowledge of phasers to analyse circuits. Students need some degree of practice to master EE course. Students need to develop ability about why, what and how a particular unknown need to be calculated. Moreover student need to connect physical phenomenon with electrical engineering quantities like electric current, flux, voltage etc. when most of these variables are time varying. And, hence, the only way to deal with this challenge is practice.
It is mandatory to get at least $40 \%$ score in two written unit tests (UT) and one in-semester-exam (ISE) which, generally, consists of two small course projects. Additionally student requires to get at least $40 \%$ score in written end semester examination (ESE) which is based on six topics while both mid-term unit tests are based on $33 \%$ course syllabus. The ISE carries $20 \%$ weightage while both UTs and ESE carries $30 \%$ and $50 \%$ weightage respectively. The grading system is as follows: FF- Fail(0-39\%), DD - Pass (40\%-50\%), CD (51\%-60\%), CC (61\%-70\%), BC (71\%-80\%), AB (81\%$90 \%)$, AA (91\%-100\%).

\section{Methodology}

\section{A. Participants and procedure}

In this study, first two units were taught to entire class consisting of 61 students without organizing webinars and providing video lectures and UT1 was conducted based on this content. In second part of experiment reaming four units of course were taught by conducting webinar using Zoom web based application as well as sharing video lectures uploaded on YouTube. After completing third and fourth units second unit test UT2 was conducted to study the impact of new methodology. Subsequently, ESE was conducted based on all six units to compare results with results obtained during earlier academic year for same course taught to other students using conventional lecturing method.

\section{B. Instruments}

In this section, the approach to enhance students learning, through webinars and video lectures, is presented for EE theory course offered to first year students. To deliver the course effectively using this approach, it is good idea to prepare power point presentation for all 36 lectures before the commencement of course. This presentation requires that all concepts are presented using suitable explanation, diagrams, and mathematical expressions with detailed derivations, animations and video clips. This presentation also need to be configured so that the use of chalk and board should be optional meaning it should be self-contained covering all aspects of the technical part to be taught during particular class. The idea is that the same presentation should be used during classroom teaching, webinar and while recording lecture using lecture capture tools. The Zoom is a web conferencing tool available in free, pro and business plans. The freely available plan has some limitations like the meeting can be planned for maximum 40 min and only 100 participants can join. For class size of less than 100, this freely available internet tool provides all required features needed for conducting online lecture such as high-quality audio, video and screen-sharing.

\section{A. Zoom Web Conferencing Tool}

The students were given training about Zoom web conferencing tool and a link was sent to all the students for free registration, before organizing first webinar. After every lecture students were informed about webinar on topic covered as well as next lecture by sending WhatsApp message containing link. The time of webinar was chosen to 
be $9.00 \mathrm{pm}$ since it was convenient to all students staying in hostel and others. Since during every webinar the power point slides used were same as that of the slides used in classroom, students found it easy to connect with all sessions. Since during every webinar the part of lecture to be conducted in future was also discussed, it was easy for slow learners especially to understand the concepts in much better manner.

\section{B. Lecture Capture Tools}

Tablet with stylus was used to record lectures by capturing the screen and using power point slides used during classroom teaching and webinars. There are many applications available to capture the screen and recording audio simultaneously. In present approach Apple iPad and Explain Edu, iOS application was used to record lectures for entire course and all recorded lectures were uploaded on YouTube to enable students to watch and learn as per their convenient time. In order to record audio with good quality sound there are many cost effective options available e.g. microphone of a smart phone. In present case, an Omnidirectional stereo microphone of Sony - ECMCS3 was used to produce good quality sound. The use of stylus helps instructor to write additional points on screen, being recorded, so that students get feel of classroom. Since recorded lectures can be played number of times, it is very convenient for students, especially slow learners understand the concepts or mathematical treatment associated with numerical questions. An iMovie software application freely available with iOS system was used for video editing.

\section{Results and Discussions}

In this section the result analysis regarding grades obtained by students in ESE and Course Outcome (CO) attainment are presented. The innovative approach presented above was implemented for first year students studying during academic year (AY), 2018-19 (1). These results are compared with results obtained during academic year, 201718(2).

\section{A. Comparison of grades obtained in ESE:}

During AY 2017-18 and 2018-19, the students registered for course were 63 and 61 respectively. During AY 2017-18, out of 61 students 12 students received fail grade which means $80 \%$ students cleared the course while during AY 2018-19 out of 63 students 11 students received fail grade which means $82.5 \%$ students cleared ESE. These results are presented in Table 1.

Table 1. Comparison of grades obtained in ESE

\begin{tabular}{|l|l|l|l|l|l|l|l|}
\hline \multirow{2}{*}{ AY } & \multicolumn{7}{|c|}{ Grades } \\
\cline { 2 - 8 } & AA & AB & BB & BC & CC & CD & DD \\
\hline$(1)$ & 04 & 09 & 10 & 12 & 09 & 06 & 02 \\
\hline$(2)$ & 00 & 00 & 06 & 11 & 24 & 11 & 07 \\
\hline
\end{tabular}

B. Comparison of Course outcomes:

The different COs defined for this course EE are given below.

CO1-Solve magnetic circuits, d.c. and a.c. electric circuits.
CO2-Describe construction, working and application of transformers.

CO3-Describe construction, working and application of different types of commonly used rotating machines.

CO4-Classify power converters on the basis of their applications.

CO5-Suggest suitable capacity of wires, cables switchgear and illumination system for low voltage electrical installations.

The comparison of $\mathrm{CO}$ attained for this course are presented in Table 2 .

Table 2. Comparison of Course Outcomes attainment (\%)

\begin{tabular}{|l|c|c|c|c|c|}
\hline \multirow{2}{*}{ AY } & \multicolumn{5}{|c|}{ COs } \\
\cline { 2 - 6 } & $\mathbf{1}$ & $\mathbf{2}$ & $\mathbf{3}$ & $\mathbf{4}$ & $\mathbf{5}$ \\
\hline$(1)$ & 73.61 & 69.26 & 76.32 & 83.62 & 81.43 \\
\hline$(2)$ & 72.95 & 60.11 & 73.32 & 57.72 & 74.88 \\
\hline
\end{tabular}

From Table 1, it can be seen that the grades of students have improved although there is no significant change in passing percentage. Moreover from Table 2, it is clear that the CO attainment during AY 218-19 is better than AY 2017-18. There are certain limitations in this approach since students located in rural areas are not connected to high speed internet services and hence participation of such students during Zoom webinar was concern.

\section{Statistical analysis}

The comparisons between results obtained for UT1 and UT2 as well as UT1 and ESE considering t-test implemented using SPSS software are presented in Table 3 and Table 4 respectively. The results are expressed as mean \pm standard error of the mean (S.E.M.) with significance at $P<0.05$. There was a significant $(P<0.05)$ enhancement in the results.

Table 3. Comparison of performance in UT1 and UT2

\begin{tabular}{|c|c|c|c|c|c|}
\hline & $\begin{array}{c}\text { Sum of } \\
\text { Squares }\end{array}$ & df & $\begin{array}{c}\text { Mean } \\
\text { Square }\end{array}$ & F & Sig. \\
\hline $\begin{array}{c}\text { Between } \\
\text { Groups } \\
\text { Within Groups }\end{array}$ & 775.195 & 1 & 775.195 & 26.695 & .000 \\
Total & 3658.922 & 126 & 29.039 & & \\
\hline
\end{tabular}

The means value of marks obtained by students during UT2 are more than that of marks obtained during UT1. Similarly it is observed that the mean of marks obtained by students during ESE is greater than marks obtained during UT1 considering percentage of marks

Table 4. Comparison of performance in UT1 and ESE

\begin{tabular}{|c|c|c|c|c|c|}
\hline Attributes & $\begin{array}{l}\text { Sum of } \\
\text { Squares }\end{array}$ & $\mathrm{df}$ & $\begin{array}{l}\text { Mean } \\
\text { Square }\end{array}$ & $\mathrm{F}$ & Sig. \\
\hline $\begin{array}{c}\text { Between } \\
\text { Groups }\end{array}$ & 1316.851 & 1 & 1316.851 & 32.446 & .000 \\
\hline Within Groups & 5113.863 & 126 & 40.586 & & \\
\hline
\end{tabular}


Total 6430.714 127

The response of students in terms of their perception regarding methodology is presented in Table 5. It can be seen that the students have given positive feedback for all three questions related to understanding

Table 5. Students' feedbacks (Course end survey).

\begin{tabular}{|l|c|c|}
\hline \multirow{2}{*}{ Questions } & \multicolumn{2}{|c|}{ Students' response } \\
\cline { 2 - 3 } & Yes & No \\
\hline $\begin{array}{l}\text { Did you find Zoom webinars and } \\
\text { YouTube video content useful to } \\
\text { understand the concepts in EE } \\
\text { course? }\end{array}$ & $100 \%$ & 0 \\
\hline $\begin{array}{l}\text { Did you notice that Zoom webinars } \\
\text { and YouTube videos helped to be } \\
\text { more active in classroom? }\end{array}$ & $100 \%$ & 0 \\
\hline $\begin{array}{l}\text { Do you feel that all courses should be } \\
\text { delivered using Zoom webinars and } \\
\text { YouTube videos created by course } \\
\text { instructor for better learning? }\end{array}$ & $100 \%$ & 0 \\
\hline
\end{tabular}

\section{Conclusions}

In this paper, an experience regarding organization of Webinars and development e-learning resources in the form of video lectures especially for slow learners is presented. The conventional teaching learning approach mostly focuses on lecturing, use of computer and projector, quizzes etc. However this approach was not effective for slow learners and help it was necessary to include some methodologies to enhance the students learning. The use of internet technology can solve the problem by having classroom content delivered through webinars and video lectures created to improve students' experience. The different challenges associated with effective implementation of different approach such as poor availability of internet facilities in rural areas, where student stay and travel to institute every day, are highlighted. The results shows that organization of webinars and video lectures can help improve learning of student. The feedback received from students was positive and students expressed that similar teaching method may be used by other course instructors for better learning of all courses.

\section{Acknowledgement}

I am thankful to Dr. S. S. Kulkarni, Director, Rajarambapu Institute of Technology, Rajaramnagar for constant support and motivation during this work.

\section{References}

Choudhury, P. K. (2016). Growth of Engineering Education in India: Status, Issues and Challenges. Higher Education for the Future, 3(1), 93-107.

Alexander, S. (2001). E-learning developments and experiences. Education+ Training, 43(4/5), 240-248.

Krathwohl, D. R. (2002). A revision of Bloom's taxonomy: An overview. Theory into practice, 41(4), 212-218.

Al-Shahrani, I. (2019). Orienting Faculty and Students with Online Teaching Webinar Experiences in Saudi Arabia. Annals of Medical and Health Sciences Research, 9(1).

Khairova, I. V., \&Toktarova, V. I. (2016). The Development of Electronic Educational Environment of the Contemporary Higher Educational Institution within the Context of Teaching Innovations. International Journal of Environmental and Science Education, 11(9), 2255-2265.

Boud, D., \&Feletti, G. (2013). The challenge of problembased learning. Routledge. 